\title{
A modified Mann iterative scheme by generalized $f$-projection for a countable family of relatively quasi-nonexpansive mappings and a system of generalized mixed equilibrium problems
}

\author{
Siwaporn Saewan ${ }^{1}$ and Poom Kumam ${ }^{1,2^{*}}$
}

\author{
* Correspondence: poom. \\ kum@kmutt.ac.th \\ 'Department of Mathematics, \\ Faculty of Science King Mongkut's \\ University of Technology Thonburi \\ (KMUTT) Bangmod, Bangkok 10140, \\ Thailand \\ Full list of author information is \\ available at the end of the article
}

\begin{abstract}
The purpose of this paper is to introduce a new hybrid projection method based on modified Mann iterative scheme by the generalized f-projection operator for a countable family of relatively quasi-nonexpansive mappings and the solutions of the system of generalized mixed equilibrium problems. Furthermore, we prove the strong convergence theorem for a countable family of relatively quasi-nonexpansive mappings in a uniformly convex and uniform smooth Banach space. Finally, we also apply our results to the problem of finding zeros of $\mathcal{B}$-monotone mappings and maximal monotone operators. The results presented in this paper generalize and improve some well-known results in the literature.

2000 Mathematics Subject Classification: 47H05; 47H09; 47H1O.

Keywords: The generalized f-projection operator, relatively quasi-nonexpansive mapping, B-monotone mappings, maximal monotone operator, system of generalized mixed equilibrium problems
\end{abstract}

\section{Introduction}

The theory of equilibrium problems, the development of an efficient and implementable iterative algorithm, is interesting and important. This theory combines theoretical and algorithmic advances with novel domain of applications. Analysis of these problems requires a blend of techniques from convex analysis, functional analysis, and numerical analysis.

Equilibrium problems theory provides us with a natural, novel, and unified framework for studying a wide class of problems arising in economics, finance, transportation, network, and structural analysis, image reconstruction, ecology, elasticity and optimization, and it has been extended and generalized in many directions. The ideas and techniques of this theory are being used in a variety of diverse areas and proved to be productive and innovative. In particular, generalized mixed equilibrium problem and equilibrium problems are related to the problem of finding fixed points of nonlinear mappings.

Let $E$ be a real Banach space with norm $\|\cdot\|, C$ be a nonempty closed convex subset of $E$ and let $E^{*}$ denote the dual of $E$. Let $\left\{\theta_{i}\right\}_{i \in \Lambda}: C \times C \rightarrow \mathbb{R}$ be a bifunction, $\left\{\phi_{i}\right\}$

(C) 2011 Saewan and Kumam; licensee Springer. This is an Open Access article distributed under the terms of the Creative Commons Attribution License (http://creativecommons.org/licenses/by/2.0), which permits unrestricted use, distribution, and reproduction in any medium, provided the original work is properly cited. 
$i \in \Lambda: C \rightarrow \mathbb{R}$ be a real-valued function, and $\left\{A_{i}\right\}_{i \in \Lambda}: C \rightarrow E^{*}$ be a monotone mapping, where $\Lambda$ is an arbitrary index set. The system of generalized mixed equilibrium problems is to find $x \in C$ such that

$$
\theta_{i}(x, y)+\left\langle A_{i} x, y-x\right\rangle+\varphi_{i}(y)-\varphi_{i}(x) \geq 0, \quad i \in \Lambda, \forall y \in C .
$$

If $\Lambda$ is a singleton, then problem (1.1) reduces to the generalized mixed equilibrium problem is to find $x \in C$ such that

$$
\theta(x, y)+\langle A x, y-x\rangle+\varphi(y)-\varphi(x) \geq 0, \quad \forall y \in C .
$$

The set of solutions to (1.2) is denoted by $\operatorname{GMEP}(\theta, A, \phi)$, i.e.,

$$
\operatorname{GMEP}(\theta, A, \varphi)=\{x \in C: \theta(x, y)+\langle A x, y-x\rangle+\varphi(y)-\varphi(x) \geq 0, \quad \forall y \in C\}
$$

If $A \equiv 0$, the problem (1.2) reduces to the mixed equilibrium problem for $\theta$, denoted by $\operatorname{MEP}(\theta, \phi)$ is to find $x \in C$ such that

$$
\theta(x, y)+\varphi(y)-\varphi(x) \geq 0, \quad \forall y \in C .
$$

If $\theta \equiv 0$, the problem (1.2) reduces to the mixed variational inequality of Browder type, denoted by $V I(C, A, \phi)$ is to find $x \in C$ such that

$$
\langle A x, y-x\rangle+\varphi(y)-\varphi(x) \geq 0, \quad \forall y \in C .
$$

If $A \equiv 0$ and $\phi \equiv 0$ the problem (1.2) reduces to the equilibrium problem for $\theta$, denoted by $\operatorname{EP}(\theta)$ is to find $x \in C$ such that

$$
\theta(x, y) \geq 0, \quad \forall y \in C .
$$

If $\theta \equiv 0$, the problem (1.4) reduces to the minimize problem, denoted by $\operatorname{Argmin}(\phi)$ is to find $x \in C$ such that

$$
\varphi(y)-\varphi(x) \geq 0, \quad \forall y \in C .
$$

The generalized mixed equilibrium problems include fixed point problems, optimization problems, variational inequality problems, Nash equilibrium problems, and the equilibrium problems as special cases. Moreover, the above formulation (1.5) was shown in [1] to cover monotone inclusion problems, saddle point problems, variational inequality problems, minimization problems, optimization problems, vector equilibrium problems, and Nash equilibria in noncooperative games. In other words, the $\operatorname{GMEP}(\theta$, $A, \phi), \operatorname{MEP}(\theta, \phi)$ and $\operatorname{EP}(\theta)$ are an unifying model for several problems arising in physics, engineering, science, optimization, economics, etc. Many authors studied and constructed some solution methods to solve the $\operatorname{GMEP}(\theta, A, \phi), \operatorname{MEP}(\theta, \phi), \operatorname{EP}(\theta)[[1-16]$, and references therein].

Let $C$ be a closed convex subset of $E$ and recall that a mapping $T: C \rightarrow C$ is said to be nonexpansive if

$$
\|T x-T y\| \leq\|x-y\|, \quad \forall x, y \in C .
$$

A point $x \in C$ is a fixed point of $T$ provided $T x=x$. Denote by $F(T)$ the set of fixed points of $T$, that is, $F(T)=\{x \in C: T x=x\}$.

As we know that if $C$ is a nonempty closed convex subset of a Hilbert space $H$ and recall that the (nearest point) projection $P_{C}$ from $H$ onto $C$ assigns to each $x \in H$, the unique point in $P_{C} x \in C$ satisfying the property $\left\|x-P_{C} x\right\|=\min _{y \in C}\|x-y\|$, then we 
also have $P_{C}$ is nonexpansive. This fact actually characterizes Hilbert spaces and consequently, it is not available in more general Banach spaces. We consider the functional defined by

$$
\phi(y, x)=\|y\|^{2}-2\langle y, J x\rangle+\|x\|^{2}, \quad \text { for } x, y \in E,
$$

where $J$ is the normalized duality mapping. In this connection, Alber [17] introduced a generalized projection $\Pi_{C}$ from $E$ in to $C$ as follows:

$$
\Pi_{C}(x)=\arg \min _{y \in C} \phi(y, x), \quad \forall x \in E .
$$

It is obvious from the definition of functional $\varphi$ that

$$
(\|y\|-\|x\|)^{2} \leq \phi(y, x) \leq(\|y\|+\|x\|)^{2}, \quad \forall x, y \in E .
$$

If $E$ is a Hilbert space, then $\varphi(y, x)=\|y-x\|^{2}$ and $\Pi_{C}$ becomes the metric projection of $E$ onto $C$. The generalized projection $\Pi_{C}: E \rightarrow C$ is a map that assigns to an arbitrary point $x \in E$ the minimum point of the functional $\varphi(y, x)$, that is, $\Pi_{C} x=\bar{x}$, where $\bar{x}$ is the solution to the minimization problem

$$
\phi(\bar{x}, x)=\inf _{y \in C} \phi(y, x) .
$$

The existence and uniqueness of the operator $\Pi_{C}$ follow from the properties of the functional $\varphi(y, x)$ and strict monotonicity of the mapping $J$ [17-21]. It is well known that the metric projection operator plays an important role in nonlinear functional analysis, optimization theory, fixed point theory, nonlinear programming, game theory, variational inequality, and complementarity problems, etc. [17,22]. In 1994, Alber [23] introduced and studied the generalized projections from Hilbert spaces to uniformly convex and uniformly smooth Banach spaces. Moreover, Alber [17] presented some applications of the generalized projections to approximately solve variational inequalities and von Neumann intersection problem in Banach spaces. In 2005, Li [22] extended the generalized projection operator from uniformly convex and uniformly smooth Banach spaces to reflexive Banach spaces and studied some properties of the generalized projection operator with applications to solve the variational inequality in Banach spaces. Later, Wu and Huang [24] introduced a new generalized $f$-projection operator in Banach spaces. They extended the definition of the generalized projection operators introduced by Abler [23] and proved some properties of the generalized $f$ projection operator. In 2009, Fan et al. [25] presented some basic results for the generalized $f$-projection operator and discussed the existence of solutions and approximation of the solutions for generalized variational inequalities in noncompact subsets of Banach spaces.

Let $\langle\cdot, \cdot\rangle$ denote the duality pairing of $E^{*}$ and $E$. Next, we recall the concept of the generalized $f$-projection operator. Let $G: C \times E^{*} \rightarrow \mathbb{R} \cup\{+\infty\}$ be a functional defined as follows:

$$
G(\xi, \varpi)=\|\xi\|^{2}-2\langle\xi, \varpi\rangle+\|\varpi\|^{2}+2 \rho f(\xi),
$$

where $\xi \in C, \varpi \in E^{*}, \rho$ is positive number and $f: C \rightarrow \mathbb{R} \cup\{+\infty\}$ is proper, convex, and lower semicontinuous. By the definitions of $G$, it is easy to see the following 
properties:

(1) $G(\xi, \varpi)$ is convex and continuous with respect to $\varpi$ when $\xi$ is fixed;

(2) $G(\xi, \varpi)$ is convex and lower semicontinuous with respect to $\xi$ when $\varpi$ is fixed.

Definition 1.1. Let $E$ be a real Banach space with its dual $E^{*}$. Let $C$ be a nonempty closed convex subset of $E$. We say that $\pi_{C}^{f}: E * \rightarrow 2^{C}$ is generalized f-projection operator if

$$
\pi_{C}^{f} \varpi=\left\{u \in C: G(u, \varpi)=\inf _{\xi \in C} G(\xi, \varpi)\right\}, \quad \forall \varpi \in E * .
$$

Observe that, if $f(x)=0$, then the generalized $f$-projection operator (1.12) reduces to the generalized projection operator (1.9).

For the generalized $f$-projection operator, Wu and Hung [24] proved the following basic properties:

Lemma 1.2. [24] Let $E$ be a real reflexive Banach space with its dual $E^{*}$ and $C$ a nonempty closed convex subset of E. Then the following statement holds:

(1) $\pi_{C}^{f} \varpi$, is a nonempty closed convex subset of $C$ for all $\omega \in E^{*}$;

(2) if $E$ is smooth, then for all $\varpi \in E^{*}, x \in \pi_{C}^{f} \varpi$ if and only if

$$
\langle x-y, \varpi-J x\rangle+\rho f(y)-\rho f(x) \geq 0, \quad \forall y \in C ;
$$

(3) if $E$ is strictly convex and $f: C \rightarrow \mathbb{R} \cup\{+\infty\}$ is positive homogeneous (i.e., $f(t x)=$ $t f(x)$ for all $t>0$ such that $t x \in C$ where $x \in C)$, then $\pi_{C}^{f} \varpi$ is single-valued mapping.

Recently, Fan et al. [25] show that the condition $f$ is positive homogeneous which appeared in [[25], Lemma 2.1 (iii)] can be removed.

Lemma 1.3. [25] Let $E$ be a real reflexive Banach space with its dual $E^{*}$ and $C$ a nonempty closed convex subset of $E$. If $E$ is strictly convex, then $\pi_{C}^{f} \varpi$ is single valued.

Recall that $J$ is single value mapping when $E$ is a smooth Banach space. There exists a unique element $\varpi \in E^{*}$ such that $\varpi=J x$ where $x \in E$. This substitution for (1.12) gives

$$
G(\xi, J x)=\|\xi\|^{2}-2\langle\xi, J x\rangle+\|x\|^{2}+2 \rho f(\xi) .
$$

Now we consider the second generalized $f$ projection operator in Banach space [26].

Definition 1.4. Let $E$ be a real smooth and Banach space and $C$ be a nonempty closed convex subset of $E$. We say that $\Pi_{C}^{f}: E \rightarrow 2^{C}$ is generalized $f$-projection operator if

$$
\Pi_{C}^{f} x=\left\{u \in C: G(u, J x)=\inf _{\xi \in C} G(\xi, J x)\right\}, \quad \forall x \in E .
$$

Next, we give the following example [27] of metric projection, generalized projection operator and generalized $f$-projection operator do not coincide. 
Example 1.5. Let $X=\mathbb{R}^{3}$ be provided with the norm $\left\|\left(x_{1}, x_{2}, x_{3}\right)\right\|=\sqrt{\left(x_{1}^{2}+x_{2}^{2}\right)}+\sqrt{x_{2}^{2}+x_{3}^{2}}$.

This is a smooth strictly convex Banach space and $C=\left\{x \in \mathbb{R}^{3} \mid x_{2}=0, x_{3}=0\right\}$ is a closed and convex subset of $X$. It is a simple computation; we get

$$
P_{C}(1,1,1)=(1,0,0), \quad \Pi_{C}(1,1,1)=(2,0,0)
$$

We set $\rho=1$ is positive number and define $f: C \rightarrow \mathbb{R} \cup\{+\infty\}$ by

$$
f(x)= \begin{cases}2+2 \sqrt{5}, & x<0 \\ -2-2 \sqrt{5}, & x \geq 0\end{cases}
$$

Then, $f$ is proper, convex, and lower semicontinuous. Simple computations show that

$$
\Pi_{C}^{f}(1,1,1)=(4,0,0) .
$$

Recall that a point $p$ in $C$ is said to be an asymptotic fixed point of $T$ [28] if $C$ contains a sequence $\left\{x_{n}\right\}$ which converges weakly to $p$ such that $\lim _{n \rightarrow \infty}\left\|x_{n}-T x_{n}\right\|=0$. The set of asymptotic fixed points of $T$ will be denoted by $\widehat{F}(T)$. A mapping $T$ from $C$ into itself is said to be relatively nonexpansive mapping [29-31] if

(R1) $F(T)$ is nonempty;

(R2) $\varphi(p, T x) \leq \varphi(p, x)$ for all $x \in C$ and $p \in F(T)$;

(R3) $\widehat{F}(T)=F(T)$.

A mapping $T$ is said to be relatively quasi-nonexpansive (or quasi- $\varphi$-nonexpansive) if the conditions (R1) and (R2) are satisfied. The asymptotic behavior of a relatively nonexpansive mapping was studied in [32-34]. The class of relatively quasi-nonexpansive mappings is more general than the class of relatively nonexpansive mappings [11,32-35] which requires the strong restriction: $F(T)=\widehat{F}(T)$. In order to explain this better, we give the following example [36] of relatively quasi-nonexpansive mappings which is not relatively nonexpansive mapping. It is clearly by the definition of relatively quasi-nonexpansive mapping $T$ is equivalent to $F(T) \neq \varnothing$, and $G(p, J T x) \leq G(p, J x)$ for all $x \in C$ and $p \in F(T)$.

Example 1.6. Let $E$ be any smooth Banach space and let $x_{0} \neq 0$ be any element of $E$.

We define a mapping $T: E \rightarrow E$ by

$$
T(x)= \begin{cases}\left(\frac{1}{2}+\frac{1}{2^{n}}\right) x_{0}, & \text { if } x=\left(\frac{1}{2}+\frac{1}{2^{n}}\right) x_{0} \\ -x, & \text { if } x \neq\left(\frac{1}{2}+\frac{1}{2^{n}}\right) x_{0} .\end{cases}
$$

Then $T$ is a relatively quasi-nonexpansive mapping but not a relatively non-expansive mapping. Actually, $T$ above fails to have the condition (R3).

Next, we give some examples which are closed quasi- $\varphi$-nonexpansive [[4], Examples 2.3 and 2.4].

Example 1.7. Let $E$ be a uniformly smooth and strictly convex Banach space and $A \subset$ $E \times E^{*}$ be a maximal monotone mapping such that its zero set $A^{-1} 0 \neq \varnothing$. Then, $J_{r}=(J$ $+r A)^{-1} J$ is a closed quasi- $\varphi$-nonexpansive mapping from $E$ onto $D(A)$ and $F\left(J_{r}\right)=A^{-1} 0$.

Proof By Matsushita and Takahashi [[35], Theorem 4.3], we see that $J_{r}$ is relatively nonexpansive mapping from $E$ onto $D(A)$ and $F\left(J_{r}\right)=A^{-1} 0$. Therefore, $J_{r}$ is quasi- $\varphi$ nonexpansive mapping from $E$ onto $D(A)$ and $F\left(J_{r}\right)=A^{-1} 0$. On the other hand, we can 
obtain the closedness of $J_{r}$ easily from the continuity of the mapping $J$ and the maximal monotonicity of $A$; see [35] for more details.

Example 1.8. Let $C$ be the generalized projection from a smooth, strictly convex, and reflexive Banach space $E$ onto a nonempty closed convex subset $C$ of $E$. Then, $C$ is a closed quasi- $\varphi$-nonexpansive mapping from $E$ onto $C$ with $F\left(\Pi_{C}\right)=C$.

In 1953, Mann [37] introduced the iteration as follows: a sequence $\left\{x_{n}\right\}$ defined by

$$
x_{n+1}=\alpha_{n} x_{n}+\left(1-\alpha_{n}\right) T x_{n}
$$

where the initial guess element $x_{1} \in C$ is arbitrary and $\left\{\alpha_{n}\right\}$ is real sequence in 0 [1]. Mann iteration has been extensively investigated for nonexpansive mappings. One of the fundamental convergence results is proved by Reich [38]. In an infinite-dimensional Hilbert space, Mann iteration can conclude only weak convergence $[39,40]$. Attempts to modify the Mann iteration method (1.14) so that strong convergence is guaranteed have recently been made. Nakajo and Takahashi [41] proposed the following modification of Mann iteration method as follows:

$$
\left\{\begin{array}{l}
x_{1}=x \in \text { Cis arbitrary, } \\
y_{n}=\alpha_{n} J x_{n}+\left(1-\alpha_{n}\right) T x_{n} \\
C_{n}=\left\{z \in C:\left\|y_{n}-z\right\| \leq\left\|x_{n}-z\right\|\right\} \\
Q_{n}=\left\{z \in C:\left\langle x_{n}-z, x-x_{n}\right\rangle \geq 0\right\} \\
x_{n+1}=P_{C_{n} \cap Q_{n}} x, n \geq 1
\end{array}\right.
$$

They proved that if the sequence $\left\{\alpha_{n}\right\}$ bounded above from one, then $\left\{x_{n}\right\}$ defined by (1.15) converges strongly to $P_{F(T)} x$.

In 2007, Aoyama et al. [[42], Lemma 3.1] introduced $\left\{T_{n}\right\}$ is a sequence of nonexpansive mappings of $C$ into itself with $\cap_{n=1}^{\infty} F\left(T_{n}\right) \neq \emptyset$ satisfy the following condition: if for each bounded subset $B$ of $C, \sum_{n=1}^{\infty} \sup \left\{\left\|T_{n+1} z-T_{n} z\right\|: z \in B<\infty\right\}$. Assume that if the mapping $T: C \rightarrow C$ defined by $T x=\lim _{n \rightarrow \infty} T_{n} x$ for all $x \in C$, then $\lim _{n \rightarrow \infty} \sup \{\|$ $\left.T z-T_{n} z||: z \in C\right\}=0$. They proved that the sequence $\left\{T_{n}\right\}$ converges strongly to some point of $C$ for all $x \in C$.

In 2009, Takahashi et al. [43] studied and proved a strong convergence theorem by the new hybrid method for a family of nonexpansive mappings in Hilbert spaces as follows: $x_{0} \in H, C_{1}=C$ and $x_{1}=P_{C_{1}} x_{0}$ and

$$
\left\{\begin{array}{c}
y_{n}=\alpha_{n} x_{n}+\left(1-\alpha_{n}\right) T_{n} x_{n}, \\
C_{n+1}=\left\{z \in C: \quad\left\|y_{n}-z\right\| \leq\left\|x_{n}-z\right\|\right\} \\
x_{n+1}=P_{C_{n+1}} x_{0}, \quad n \geq 1,
\end{array}\right.
$$

where $0 \leq \alpha_{n} \leq a<1$ for all $n \in \infty$ and $\left\{T_{n}\right\}$ is a sequence of nonexpansive mappings of $C$ into itself such that $\cap_{n=1}^{\infty} F\left(T_{n}\right) \neq \emptyset$. They proved that if $\left\{T_{n}\right\}$ satisfies some appropriate conditions, then $\left\{x_{n}\right\}$ converges strongly to $P_{\cap_{n=1}^{\infty} F\left(T_{n}\right)} x_{0}$.

The ideas to generalize the process (1.14) from Hilbert spaces have recently been made. By using available properties on a uniformly convex and uniformly smooth Banach space, Matsushita and Takahashi [35] proposed the following hybrid iteration method with generalized projection for relatively nonexpansive mapping $T$ in a Banach space $E$ : 


$$
\left\{\begin{array}{l}
x_{0} \in C \text { chosen arbitrarily, } \\
y_{n}=J^{-1}\left(\alpha_{n} J x_{n}+\left(1-\alpha_{n}\right) J T x_{n}\right) \\
C_{n}=\left\{z \in C: \phi\left(z, y_{n}\right) \leq \phi\left(z, x_{n}\right)\right\} \\
Q_{n}=\left\{z \in C:\left\langle x_{n}-z, J x_{0}-J x_{n}\right\rangle \geq 0\right\} \\
x_{n+1}=\Pi_{C_{n} \cap Q_{n}} x_{0} .
\end{array}\right.
$$

They proved that $\left\{x_{n}\right\}$ converges strongly to $\Pi_{F(T)} x_{0}$, where $\Pi_{F(T)}$ is the generalized projection from $C$ onto $F(T)$. Plubtieng and Ungchittrakool [44] introduced and proved the processes for finding a common fixed point of a countable family of relatively nonexpansive mappings in a Banach space. They proved the strong convergence theorems for a common fixed point of a countable family of relatively nonexpansive mappings $\left\{T_{n}\right\}$ provided that $\left\{T_{n}\right\}$ satisfies the following condition:

- if for each bounded subset $D$ of $C$, there exists a continuous increasing and convex function $h: \mathbb{R}^{+} \rightarrow \mathbb{R}^{+}$. such that $h(0)=0$ and $\lim k_{l \rightarrow \infty} \sup _{z \in D} h\left(\left\|T_{k} z-T_{l} z\right\|\right)$ $=0$.

Motivated by the results of Takahashi and Zembayashi [13], Cholumjiak and Suantai [2] proved the following strong convergence theorem by the hybrid iterative scheme for approximation of common fixed point of countable families of relatively quasi-nonexpansive mappings $\left\{T_{i}\right\}$ on $C$ into itself in a uniformly convex and uniformly smooth Banach space: $x_{0} \in E, x_{1}=\Pi_{C_{1}} x_{0}, C_{1}=C$

$$
\left\{\begin{array}{l}
y_{n, i}=J^{-1}\left(\alpha_{n} J x_{n}+\left(1-\alpha_{n}\right) J T_{i} x_{n}\right), \\
u_{n, i}=T_{r_{m, n}}^{F_{m}} T_{r_{m-1, n}}^{F_{m-1}} \ldots T_{r_{1, n}}^{F_{1}} y_{n, i} \\
C_{n+1}=\left\{z \in C_{n}: \sup _{i>1} \phi\left(z, J u_{n, i}\right) \leq \phi\left(w, J x_{n}\right)\right\} \\
x_{n+1}=\Pi_{C_{n+1}} x_{0}, n \geq 1,
\end{array}\right.
$$

where $T_{r_{i, n},}^{F_{i}}, i=1,2,3, \ldots, m$ defined in Lemma 2.8. Then, they proved that under certain appropriate conditions imposed on $\left\{\alpha_{n}\right\}$, and $\left\{r_{n, i}\right\}$, the sequence $\left\{x_{n}\right\}$ converges strongly to $\Pi_{C_{n+1}} x_{0}$.

Recently, Li et al. [26] introduced the following hybrid iterative scheme for approximation of fixed point of relatively nonexpansive mapping using the properties of generalized $f$-projection operator in a uniformly smooth real Banach space which is also uniformly convex: $x_{0} \in C$,

$$
\left\{\begin{array}{l}
y_{n}=J^{-1}\left(\alpha_{n} J x_{n}+\left(1-\alpha_{n}\right) J T x_{n}\right) \\
C_{n+1}=\left\{w \in C_{n}: G\left(w, J y_{n}\right) \leq G\left(w, J x_{n}\right)\right\} \\
x_{n+1}=\Pi_{C_{n+1}}^{f} x_{0}, n \geq 1
\end{array}\right.
$$

They obtained a strong convergence theorem for finding an element in the fixed point set of $T$. The results of $\mathrm{Li}$ et al. [26] extended and improved on the results of Matsushita and Takahashi [35].

Very recently, Shehu [45] studied and obtained the following strong convergence theorem by the hybrid iterative scheme for approximation of common fixed point of finite family of relatively quasi-nonexpansive mappings in a uniformly convex and uniformly smooth Banach space: let $x_{0} \in C, x_{1}=\Pi_{C_{1}} x_{0}, C_{1}=C$ and 


$$
\left\{\begin{array}{l}
y_{n}=J^{-1}\left(\alpha_{n} J x_{n}+\left(1-\alpha_{n}\right) J T_{n} x_{n}\right) \\
u_{n}=T_{r_{m, n}}^{F_{m}} T_{r_{m-1, n}}^{F_{m-1}} \ldots T_{r_{1, n}}^{F_{1}} y_{n} \\
C_{n+1}=\left\{z \in C_{n}: \phi\left(z, u_{n}\right) \leq \phi\left(z, x_{n}\right)\right\} \\
x_{n+1}=\prod_{C_{n+1}} x_{0}, n \geq 1
\end{array}\right.
$$

where $T_{n}=T_{n}(\bmod N)$. He proved that the sequence $\left\{x_{n}\right\}$ converges strongly to $\Pi_{C_{n+1}} x_{0}$ under certain appropriate conditions.

Recall that a mapping $T: C \rightarrow C$ is closed if for each $\left\{x_{n}\right\}$ in $C$, if $x_{n} \rightarrow x$ and $T x_{n} \rightarrow$ $y$, then $T x=y$. Let $\left\{T_{n}\right\}$ be a family of mappings of $C$ into itself with $\mathcal{F}:=\cap_{n=1}^{\infty} F\left(T_{n}\right) \neq \emptyset,\left\{T_{n}\right\}$ is said to satisfy the (*)-condition [46] if for each bounded sequence $\left\{z_{n}\right\}$ in $C$,

$$
\lim _{n \rightarrow \infty}\left\|z_{n}-T_{n} z_{n}\right\|=0, \quad \text { and } \quad z_{n} \rightarrow z \text { imply } z \in \mathcal{F} .
$$

It follows directly from the definitions above that if $T_{n} \equiv T$ and $T$ is closed, then $\left\{T_{n}\right\}$ satisfies (")-condition [46]. Next, we give the following example:

Example 1.9. Let $E=\mathbb{R}$ with the usual norm. We define a mapping $T_{n}: E \rightarrow E$ by

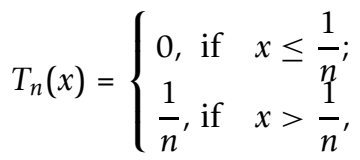

for all $n \geq 0$ and for each $x \in \mathbb{R}$. Hence, $\bigcap_{n=1}^{\infty} F\left(T_{n}\right)=F\left(T_{n}\right)=\{0\}$ and $\varphi\left(0, T_{n} x\right)=\|$ $0-T_{n} x\|\leq\| 0-x \|=\varphi(0, x), \forall x \in \mathbb{R}$. Then, $T$ is a relatively quasi-nonexpansive mapping but not a relatively nonexpansive mapping. Moreover, for each bounded sequence $z_{n} \in E$, we observe that $T_{n} z_{n}=\frac{1}{n} \rightarrow 0$ as $n \rightarrow \infty$, and hence $z=\lim _{n \rightarrow \infty} z_{n}=\lim _{n \rightarrow \infty}$ $T_{n} z_{n}=0$ as $n \rightarrow \infty$; this implies that $z=0 \in F\left(T_{n}\right)$. Therefore, $T_{n}$ is a relatively quasinonexpansive mapping and satisfies the $(*)$-condition.

In 2010, Shehu [47] introduced a new iterative scheme by hybrid methods and proved strong convergence theorem for approximation of a common fixed point of two countable families of weak relatively nonexpansive mappings which is also a solution to a system of generalized mixed equilibrium problems in a uniformly convex real Banach space which is also uniformly smooth using the properties of generalized $f$-projection operator.

The following questions naturally arise in connection with the above results using the (")-condition:

Question 1: Can the Mann algorithms (1.20) of [45] still be valid for an infinite family of relatively quasi-nonexpansive mappings?

Question 2: Can an iterative scheme (1.19) to solve a system of generalized mixed equilibrium problems?

Question 3: Can the Mann algorithms (1.20) be extended to more generalized f-projection operator?

The purpose of this paper is to solve the above questions. We introduce a new hybrid iterative scheme of the generalized $f$-projection operator for finding a common element of the fixed point set for a countable family of relatively quasi-nonexpansive mappings and the set of solutions of the system of generalized mixed equilibrium problem in a uniformly convex and uniformly smooth Banach space by using the (*)-condition. Furthermore, we show that our new iterative scheme converges strongly to a 
common element of the aforementioned sets. Our results extend and improve the recent result of Li et al. [26], Matsushita and Takahashi [35], Takahashi et al. [43], Nakajo and Takahashi [41] and Shehu [45] and others.

\section{Preliminaries}

A Banach space $E$ is said to be strictly convex if $\left\|\frac{x+y}{2}\right\|<1$ for all $x, y \in E$ with $\|x\|=$ $\|y\|=1$ and $x \neq y$. Let $U=\{x \in E:\|x\|=1\}$ be the unit sphere of $E$. Then a Banach space $E$ is said to be smooth if the $\operatorname{limit}_{t \rightarrow 0} \frac{\|x+t y||-|| x\| \mid}{t}$ exists for each $x, y \in U$. It is also said to be uniformly smooth if the limit exists uniformly in $x, y \in U$. Let $E$ be a Banach space. The modulus of smoothness of $E$ is the function $\rho_{E}:[0, \infty] \rightarrow[0, \infty]$ defined by $\rho_{E}(t)=\sup \left\{\frac{\|x+y\|+\|x-y\|}{2}-1:\|x\|=1,\|y\| \leq t\right\}$. The modulus of convexity of $E$ is the function $\delta_{E}:\left[\begin{array}{ll}0, & 2\end{array}\right] \rightarrow\left[\begin{array}{ll}0, & 1\end{array}\right]$ defined by $\delta_{E}(\varepsilon)=\inf \left\{1-\left\|\frac{x+y}{2}\right\|: x, y \in E,\|x\|=\|y\|=1,\|x-y\| \geq \varepsilon\right\}$. The normalized duality mapping $J: E \rightarrow 2^{E *}$ is defined by $J(x)=\left\{x^{*} \in E^{* *}:\left\langle x, x^{*}\right\rangle=\|x\|^{2},\left\|x^{*}\right\|=\|x\|\right\}$. If $E$ is a Hilbert space, then $J=I$, where $I$ is the identity mapping.

It is also known that if $E$ is uniformly smooth, then $J$ is uniformly norm-to-norm continuous on each bounded subset of $E$.

Remark 2.1. If $E$ is a reflexive, strictly convex and smooth Banach space, then for $x, y$ $\in E, \varphi(x, y)=0$ if and only if $x=y$. It is sufficient to show that if $\varphi(x, y)=0$ then $x=$ $y$. From (1.8), we have $\|x\|=\|y\|$. This implies that $\langle x, J y\rangle=\|x\|^{2}=\|J y\|^{2}$. From the definition of $J$, one has $J x=J y$. Therefore, we have $x=y$; see [19,21] for more details.

We also need the following lemmas for the proof of our main results:

Lemma 2.2. [20]Let E be a uniformly convex and smooth Banach space and let $\left\{x_{n}\right\}$ and $\left\{y_{n}\right\}$ be two sequences of E. If $\varphi\left(x_{n}, y_{n}\right) \rightarrow 0$ and either $\left\{x_{n}\right\}$ or $\left\{y_{n}\right\}$ is bounded, then $\left\|x_{n}-y_{n}\right\| \rightarrow 0$.

Lemma 2.3. [48] Let $E$ be a Banach space and $f: E \rightarrow \mathbb{R} \cup\{+\infty\}$ be a lower semicontinuous convex functional. Then there exist $x^{*} \in E^{*}$ and $\alpha \in \mathbb{R}$ such that

$$
f(x) \geq\langle x, x *\rangle+\alpha, \forall x \in E
$$

Lemma 2.4. [26] Let $E$ be a reflexive smooth Banach space and $C$ be a nonempty closed convex subset of $E$. The following statements hold:

1. $\Pi_{C}^{f} x$ is nonempty closed convex subset of $C$ for all $x \in E$;

2. for all $x L E, \hat{x} \in \Pi_{C}^{f} x i f$ and only if

$$
\langle\hat{x}-y, J x-J \hat{x}\rangle+\rho f(y)-\rho f(\hat{x}) \geq 0, \quad \forall y \in C ;
$$

3. if $E$ is strictly convex, then $\Pi_{C}^{f}$ is a single-valued mapping.

Lemma 2.5. [26] Let $E$ be a real reflexive smooth Banach space, let $C$ be a nonempty closed convex subset of $E$, and let $\hat{x} \in \Pi_{C}^{f} x$. Then

$$
\phi(y, \hat{x})+G(\hat{x}, J x) \leq G(y, J x), \quad \forall y \in C .
$$


Remark 2.6. Let $E$ be a uniformly convex and uniformly smooth Banach space and $f$ $(x)=0$ for all $x \in E$; then Lemma 2.5 reduces to the property of the generalized projection operator considered by Alber [17].

Lemma 2.7. [4] Let E be a real uniformly smooth and strictly convex Banach space, and $C$ be a nonempty closed convex subset of E. Let $T: C \rightarrow C$ be a closed and relatively quasi-nonexpansive mapping. Then $F(T)$ is a closed and convex subset of $C$.

For solving the equilibrium problem for a bifunction $\theta: C \times C \rightarrow \mathbb{R}$, let us assume that $\theta$ satisfies the following conditions:

(A1) $\theta(x, x)=0$ for all $x \in C$;

(A2) $\theta$ is monotone, i.e., $\theta(x, y)+\theta(y, x) \leq 0$ for all $x, y \in C$;

(A3) for each $x, y, z \in C$,

$$
\lim _{t \downarrow 0} \theta(t z+(1-t) x, y) \leq \theta(x, y) ;
$$

(A4) for each $x \in C, y \mapsto \theta(x, y)$ is convex and lower semi-continuous.

For example, let $A$ be a continuous and monotone operator of $C$ into $E^{* *}$ and define

$$
\theta(x, y)=\langle A x, y-x\rangle, \forall x, y \in C .
$$

Then, $\theta$ satisfies (A1)-(A4). The following result is in Blum and Oettli [1].

Motivated by Combettes and Hirstoaga [3] in a Hilbert space and Taka-hashi and Zembayashi [12] in a Banach space, Zhang [16] obtain the following lemma:

Lemma 2.8. Let $C$ be a closed convex subset of a smooth, strictly convex and reflexive Banach space $E$. Assume that $\theta$ be a bifunction from $C \times C$ to $\mathbb{R}$ satisfying (A1)-(A4), $A$ $: C \rightarrow E^{*}$ be a continuous and monotone mapping and $\phi: C \rightarrow \mathbb{R}$ be a semicontinuous and convex functional. For $r>0$ and let $x \in E$. Then, there exists $z \in C$ such that

$$
F(z, y)+\frac{1}{r}\langle y-z, J z-J x\rangle \geq 0, \quad \forall y \in C .
$$

where $F(z, y)=\theta(x, y)+\langle A z, y-z\rangle+\phi(y)-\phi(x), x, y \in C$. Furthermore, define a mapping $T_{r}^{F}: E \rightarrow$ Cas follows:

$$
T_{r}^{F} x=\left\{z \in C: F(z, y)+\frac{1}{r}\langle y-z, J z-J x\rangle \geq 0, \quad \forall y \in C\right\} .
$$

Then the following hold:

(1) $T_{r}^{F}$ is single-valued;

(2) $T_{r}^{F}$ is firmly nonexpansive, i.e., for all $x, y \in E$, $\left\langle T_{r}^{F} x-T_{r}^{F} y, J T_{r}^{F} x-J T_{r}^{F} y\right\rangle \leq\left\langle T_{r}^{F} x-T_{r}^{F} y, J x-J y\right\rangle ;$

(3) $F\left(T_{r}^{F}\right)=\widehat{F}\left(T_{r}^{F}\right)=\operatorname{GMEP}(\theta, A, \varphi)$;

(4) $\operatorname{GMEP}(\theta, A, \phi)$ is closed and convex;

(5) $\phi\left(p, T_{r}^{F} z\right)+\phi\left(T_{r}^{F} z, z\right) \leq \phi(p, z), \forall p \in F\left(T_{r}^{F}\right)$ and $z \in E$.

\section{Main results}

In this section, by using the (*)-condition, we prove the new convergence theorems for finding a common fixed points of a countable family of relatively quasi-nonexpansive mappings, in a uniformly convex and uniformly smooth Banach space. 
Theorem 3.1. Let $C$ be a nonempty closed and convex subset of a uniformly convex and uniformly smooth Banach space E. Let $\left\{T_{n}\right\}_{n=1}^{\infty}$ be a countable family of relatively quasi-nonexpansive mappings of $C$ into $E$ satisfy the $\left({ }^{*}\right)$-condition and $f: E \rightarrow \mathbb{R}$ be a convex lower semicontinuous mapping with $C \subset \operatorname{int}(D(f)$, where $D(f)$ is a domain of $f$. For each $j=1,2, \ldots, m$ let $\theta_{j}$ be a bifunction from $C \times C$ to $\mathbb{R}$ which satisfies conditions (A1)-(A4), $A_{j}: C \rightarrow E^{*}$ be a continuous and monotone mapping, and $\phi_{j}: C \rightarrow \mathbb{R}$ be a lower semicontinuous and convex function. Assume that $\mathfrak{F}:=\left(\cap_{n=1}^{\infty} F\left(T_{n}\right)\right) \bigcap\left(\cap_{j=1}^{m} \operatorname{GMEP}\left(\theta_{j}, A_{j}, \varphi_{j}\right)\right) \neq \emptyset$. For an initial point $x_{0} \in E$ with $x_{1}=\Pi_{C_{1}}^{f} x_{0}$ and $C_{1}=C$, we define the sequence $\left\{x_{n}\right\}$ as follows:

$$
\left\{\begin{array}{l}
y_{n}=J^{-1}\left(\alpha_{n} J x_{n}+\left(1-\alpha_{n}\right) J T_{n} x_{n}\right), \\
u_{n}=T_{r_{m, n}}^{F_{m}} T_{r_{m-1, n}}^{F_{m-1}} \ldots, T_{r_{2, n}, F_{2}}^{F_{2}} T_{1_{1, n}}^{F_{1}} y_{n}, \\
C_{n+1}=\left\{z \in C_{n}: G\left(z, J u_{n}\right) \leq G\left(z, J y_{n}\right) \leq G\left(z, J x_{n}\right)\right\}, \\
x_{n+1}=\Pi_{C_{n+1}}^{f} x_{0}, \quad n \geq 1,
\end{array}\right.
$$

where $J$ is the duality mapping on $E,\left\{\alpha_{n}\right\}$ is a sequence in $[0,1]$ and $\left\{r_{j, n}\right\}_{n=1}^{\infty} \subset[d, \infty)$ for some $d>0(j=1,2, \ldots, m)$. If $\lim _{\inf _{n \rightarrow \infty}}\left(1-\alpha_{n}\right)>0$, then $\left\{x_{n}\right\}$ converges strongly to $p \in \mathfrak{F}$, where $p=\Pi_{\mathfrak{F}}^{f} x_{0}$.

Proof We split the proof into five steps.

Step 1: We first show that $C_{n}$ is closed and convex for each $n \in \mathbb{N}$.

Clearly $C_{1}=C$ is closed and convex. Suppose that $C_{n}$ is closed and convex for each $n \in \mathbb{N}$. Since for any $z \in C_{n}$, we know $G\left(z, J u_{n}\right) \leq G\left(z, J x_{n}\right)$ is equivalent to

$$
2\left\langle z, J x_{n}-J u_{n}\right\rangle \leq\left\|x_{n}\right\|^{2}-\left\|u_{n}\right\|^{2} .
$$

So, $C_{n+1}$ is closed and convex. This implies that $\Pi_{C_{n+1}}^{f} x_{0}$ is well defined.

Step 2 : We show that $\mathfrak{F} \subset C_{n}$ for all $n \in \mathbb{N}$.

Next, we show by induction that $\mathfrak{F} \subset C_{n}$ for all $n \in \mathbb{N}$. It is obvious that $\mathfrak{F} \subset C=C_{1}$. Suppose that $\mathfrak{F} \subset C_{n}$ for some $n \in \mathbb{N}$. Let $q \in \mathfrak{F}$ and $u_{n}=K_{n}^{m} y_{n}$, when $K_{n}^{j}=T_{r_{j, n}}^{F_{j}} T_{r_{j-1, n}}^{F_{j-1}} \ldots, T_{r_{2, n}}^{F_{2}} T_{r_{1, n}}^{F_{1}}, j=1,2,3, \ldots, m, K_{n}^{0}=I$; since $\left\{T_{n}\right\}$ is relatively quasi-nonexpansive mappings, it follows by (3.2) that

$$
\begin{aligned}
G\left(q, J u_{n}\right)= & G\left(q, J K_{n}^{m} y_{n}\right) \\
\leq & G\left(q, J y_{n}\right) \\
= & G\left(q, \alpha_{n} J x_{n}+\left(1-\alpha_{n}\right) J T_{n} x_{n}\right) \\
= & \|q\|^{2}-2\left\langle q, \alpha_{n} J x_{n}+\left(1-\alpha_{n}\right) J T_{n} x_{n}\right\rangle \\
& +\left\|\alpha_{n} J x_{n}+\left(1-\alpha_{n}\right) J T_{n} x_{n}\right\|^{2}+2 \rho f(q) \\
\leq & \|q\|^{2}-2 \alpha_{n}\left\langle q, J x_{n}\right\rangle-2\left(1-\alpha_{n}\right)\left\langle q, J T_{n} x_{n}\right\rangle \\
& +\alpha_{n}\left\|J x_{n}\right\|^{2}+\left(1-\alpha_{n}\right)\left\|J T_{n} x_{n}\right\|^{2}+2 \rho f(q) \\
= & \alpha_{n} G\left(q, J x_{n}\right)+\left(1-\alpha_{n}\right) G\left(q, J T_{n} x_{n}\right) \\
\leq & \alpha_{n} G\left(q, J x_{n}\right)+\left(1-\alpha_{n}\right) G\left(q, J x_{n}\right) \\
= & G\left(q, J x_{n}\right) .
\end{aligned}
$$

This shows that $q \in C_{n+1}$ which implies that $\mathfrak{F} \subset C_{n+1}$ and hence, $\mathfrak{F} \subset C_{n}$ for all $n \in$ $\mathbb{N}$.

Step 3 : We show that $\left\{x_{n}\right\}$ is a Cauchy sequence in $C$ and $\lim _{n \rightarrow \infty} G\left(x_{n}, J x_{0}\right)$ exist.

Since $f: E \rightarrow \mathbb{R}$ is convex and lower semicontinuous mapping, from Lemma 2.3, we know that there exist $x^{*} \in E^{*}$ and $\alpha \in \mathbb{R}$ such that 


$$
f(y) \geq\left\langle y, x^{*}\right\rangle+\alpha, \forall y \in E .
$$

Since $x_{n} \in E$, it follows that

$$
\begin{aligned}
G\left(x_{n}, J x_{0}\right) & =\left\|x_{n}\right\|^{2}-2\left\langle x_{n}, J x_{0}\right\rangle+\left\|x_{0}\right\|^{2}+2 \rho f\left(x_{n}\right) \\
& \geq\left\|x_{n}\right\|^{2}-2\left\langle x_{n}, J x_{0}\right\rangle+\left\|x_{0}\right\|^{2}+2 \rho\left\langle x_{n}, x^{*}\right\rangle+2 \rho \alpha \\
& =\left\|x_{n}\right\|^{2}-2\left\langle x_{n}, J x_{0}-\rho x^{*}\right\rangle+\left\|x_{0}\right\|^{2}+2 \rho \alpha \\
& \geq\left\|x_{n}\right\|^{2}-2\left\|x_{n}\right\|\|\mid\| x_{0}-\rho x^{*}\|+\| x_{0} \|^{2}+2 \rho \alpha \\
& =\left(\left\|x_{n}\right\|-\left\|J x_{0}-\rho x^{*}\right\|\right)^{2}+\left\|x_{0}\right\|^{2}-\left\|J x_{0}-\rho x^{*}\right\|^{2}+2 \rho \alpha .
\end{aligned}
$$

Again since $x_{n}=\Pi_{C_{n}}^{f} x_{0}$ and from (3.3), we have

$$
\begin{aligned}
G\left(q, J x_{0}\right) \geq & G\left(x_{n}, J x_{0}\right) \geq\left(\left\|x_{n}\right\|-\left\|J x_{0}-\rho x^{*}\right\|\right)^{2} \\
& +\left\|x_{0}\right\|^{2}-\left\|J x_{0}-\rho x^{*}\right\|^{2}+2 \rho \alpha, \quad \forall q \in \mathcal{F} .
\end{aligned}
$$

This implies that $\left\{x_{n}\right\}$ is bounded and so are $\left\{G\left(x_{n}, J x_{0}\right)\right\},\left\{y_{n}\right\}$ and $\left\{u_{n}\right\}$. From the fact that $x_{n+1}=\Pi_{C_{n+1}}^{f} x_{0} \in C_{n+1} \subset C_{n}$ and $x_{n}=\Pi_{C_{n}}^{f} x_{0}$, it follows by Lemma 2.5, we get

$$
0 \leq\left(\left\|x_{n+1}-\right\| x_{n} \|\right)^{2} \leq \phi\left(x_{n+1}, x_{n}\right) \leq G\left(x_{n+1}, J x_{0}\right)-G\left(x_{n}, J x_{0}\right) .
$$

This implies that $\left\{G\left(x_{n}, J x_{0}\right)\right\}$ is nondecreasing. So, we obtain that $\lim _{n \rightarrow \infty} G\left(x_{n}, J x_{0}\right)$ exist. For $m>n, x_{n}=\prod_{C_{n}}^{f} x_{0}, x_{m}=\prod_{C_{m}}^{f} x_{0} \in C_{m} \subset C_{n}$ and from (3.4), we have

$$
\phi\left(x_{m}, x_{n}\right) \leq G\left(x_{m}, J x_{0}\right)-G\left(x_{n}, J x_{0}\right) \text {. }
$$

Taking $m, n \rightarrow \infty$, we have $\varphi\left(x_{m}, x_{n}\right) \rightarrow 0$. From Lemma 2.2, we get $\left\|x_{n}-x_{m}\right\| \rightarrow 0$. Hence, $\left\{x_{n}\right\}$ is a Cauchy sequence and by the completeness of $E$ and the closedness of $C$, we can assume that there exists $p \in C$ such that $x_{n} \rightarrow p \in C$ as $n \rightarrow \infty$.

Step 4: We will show that $p \in \mathfrak{F}:=\left(\cap_{n=1}^{\infty} F\left(T_{n}\right)\right) \cap\left(\cap_{j=1}^{m} \operatorname{GMEP}\left(\theta_{j}, A_{j}, \varphi_{j}\right)\right.$.

(a) We show that $p \in \cap_{n=1}^{\infty} F\left(T_{n}\right)$. Since $\varphi\left(x_{m}, x_{n}\right) \rightarrow 0$ as $m, n \rightarrow \infty$, we obtain in particular that $\varphi\left(x_{n+1}, x_{n}\right) \rightarrow 0$ as $n \rightarrow \infty$. By Lemma 2.2, we have

$$
\lim _{n \rightarrow \infty}\left\|x_{n+1}-x_{n}\right\|=0 .
$$

Since $J$ is uniformly norm-to-norm continuous on bounded subsets of $E$, we also have

$$
\lim _{n \rightarrow \infty}\left\|J x_{n+1}-J x_{n}\right\|=0 .
$$

From the definition of $x_{n+1}=\Pi_{C_{n+1}}^{f} x_{0} \in C_{n+1} \subset C_{n}$, we have

$$
G\left(x_{n+1}, J u_{n}\right) \leq G\left(x_{n+1}, J x_{n}\right), \quad \forall n \in \mathbb{N},
$$

is equivalent to

$$
\phi\left(x_{n+1}, u_{n}\right) \leq \phi\left(x_{n+1}, x_{n}\right), \quad \forall n \in \mathbb{N} .
$$

It follows that

$$
\lim _{n \rightarrow \infty} \phi\left(x_{n+1}, u_{n}\right)=0 .
$$

By applying Lemma 2.2, we have

$$
\lim _{n \rightarrow \infty}\left\|x_{n+1}-u_{n}\right\|=0 .
$$


By the triangle inequality, we have

$$
\begin{aligned}
\left\|u_{n}-x_{n}\right\| & =\left\|u_{n}-x_{n+1}+x_{n+1}-x_{n}\right\| \\
& \leq\left\|u_{n}-x_{n+1}\right\|+\left\|x_{n+1}-x_{n}\right\|
\end{aligned}
$$

It follows from (3.5) and (3.8), that

$$
\lim _{n \rightarrow \infty}\left\|u_{n}-x_{n}\right\|=0 .
$$

Since $J$ is uniformly norm-to-norm continuous on bounded subsets of $E$, we also have

$$
\lim _{n \rightarrow \infty}\left\|J u_{n}-J x_{n}\right\|=0 .
$$

From $x_{n+1}=\Pi_{C_{n+1}}^{f} x_{0} \in C_{n+1} \subset C_{n}$ and the definition of $C_{n+1}$, we get

$$
\mathrm{G}\left(x_{n+1}, J y_{n}\right) \leq \mathrm{G}\left(x_{n+1}, J x_{n}\right)
$$

is equivalent to

$$
\phi\left(x_{n+1}, y_{n}\right) \leq \phi\left(x_{n+1}, x_{n}\right) .
$$

Using Lemma 2.2, we have

$$
\lim _{n \rightarrow \infty}\left\|x_{n+1}-y_{n}\right\|=0 \text {. }
$$

Since $J$ is uniformly norm-to-norm continuous, we obtain

$$
\lim _{n \rightarrow \infty}\left\|J x_{n+1}-J y_{n}\right\|=0 .
$$

Noticing that

$$
\begin{aligned}
\left\|J x_{n+1}-J y_{n}\right\| & =\left\|J x_{n+1}-\alpha_{n} J x_{n}-\left(1-\alpha_{n}\right) J T_{n} x_{n}\right\| \\
& =\left\|\left(1-\alpha_{n}\right) J x_{n+1}-\left(1-\alpha_{n}\right) J T_{n} x_{n}+\alpha_{n} J x_{n+1}-\alpha_{n} J x_{n}\right\| \\
& \geq\left(1-\alpha_{n}\right)\left\|J x_{n+1}-J T_{n} x_{n}\right\|-\alpha_{n}\left\|J x_{n}-J x_{n+1}\right\|,
\end{aligned}
$$

we have

$$
\left\|J x_{n+1}-J T_{n} x_{n}\right\| \leq \frac{1}{\left(1-\alpha_{n}\right)}\left(\left\|J x_{n+1}-J y_{n}\right\|+\alpha_{n}\left\|J x_{n}-J x_{n+1}\right\|\right),
$$

since $\lim \inf _{n \rightarrow \infty}\left(1-\alpha_{n}\right)>0,(3.6)$ and (3.12), one has

$$
\lim _{n \rightarrow \infty}\left\|J x_{n+1}-J T_{n} x_{n}\right\|=0 .
$$

Since $J^{1}$ is uniformly norm-to-norm continuous, we obtain

$$
\lim _{n \rightarrow \infty}\left\|x_{n+1}-T_{n} x_{n}\right\|=0 .
$$

Using the triangle inequality, we have

$$
\left\|x_{n}-T_{n} x_{n}\right\| \leq\left\|x_{n}-x_{n+1}\right\|+\left\|x_{n+1}-T_{n} x_{n}\right\| .
$$

From (3.5) and (3.16), we have

$$
\lim _{n \rightarrow \infty}\left\|x_{n}-T_{n} x_{n}\right\|=0 .
$$

Since $x_{n} \rightarrow p$ it follows from the $(*)$-condition that $p \in \mathfrak{F}=\cap_{n=0}^{\infty} F\left(T_{n}\right)$. 
(b) We show that $p \in \cap_{j=1}^{m} \operatorname{GMEP}\left(\theta_{j}, A_{j}, \varphi_{j}\right)$.

For $q \in \mathfrak{F}$, we have

$$
\begin{aligned}
\phi\left(q, x_{n}\right)-\phi\left(q, u_{n}\right) & =\left\|x_{n}\right\|^{2}-\left\|u_{n}\right\|^{2}-2\left\langle q, J x_{n}-J u_{n}\right\rangle \\
& \leq\left\|x_{n}-u_{n}\right\|\left(\left\|x_{n}\right\|+\left\|u_{n}\right\|\right)+2\|q\|\left\|J x_{n}-J u_{n}\right\| .
\end{aligned}
$$

From $\left\|x_{n}-u_{n}\right\| \rightarrow 0$ and $\left\|J x_{n}-J u_{n}\right\| \rightarrow 0$, that

$$
\phi\left(q, x_{n}\right)-\phi\left(q, u_{n}\right) \rightarrow 0 \text { as } n \rightarrow \infty
$$

Let $u_{n}=K_{n}^{m} y_{n}$; when $K_{n}^{j}=T_{r_{j, n}}^{F_{j}} T_{r_{j-1, n}}^{F_{j-1}}, \ldots, T_{r_{2, n}}^{F_{2}} T_{r_{1, n}}^{F_{1}}, j=1,2,3, \ldots, m$ and $K_{n}^{0}=I$, we obtain that

$$
\begin{aligned}
\phi\left(q, u_{n}\right)= & \phi\left(q, K_{n}^{m} y_{n}\right) \\
\leq & \phi\left(q, K_{n}^{m-1} y_{n}\right) \\
\leq & \phi\left(q, K_{n}^{m-2} y_{n}\right) \\
& \vdots \\
\leq & \phi\left(q, K_{n}^{j} y_{n}\right) .
\end{aligned}
$$

By Lemma 2.8(5), we have for $j=1,2,3, \ldots, m$

$$
\begin{aligned}
\phi\left(K_{n}^{j} y_{n}, y_{n}\right) & \leq \phi\left(q, y_{n}\right)-\phi\left(q, K_{n}^{j} y_{n}\right) \\
& \leq \phi\left(q, x_{n}\right)-\phi\left(q, K_{n}^{j} y_{n}\right) \\
& \leq \phi\left(q, x_{n}\right)-\phi\left(q, u_{n}\right) .
\end{aligned}
$$

By (3.18), we have $\phi\left(K_{n}^{j} y_{n}, y_{n}\right) \rightarrow 0$ as $n \rightarrow \infty$, for $j=1,2,3, \ldots, m$. By Lemma 2.2, we obtain

$$
\lim _{n \rightarrow \infty}\left\|K_{n}^{j} y_{n}-y_{n}\right\|=0, \quad \forall j=1,2,3, \ldots, m .
$$

Since $\left\|x_{n}-y_{n}\right\| \leq\left\|x_{n}-x_{n+1}\right\|+\left\|x_{n+1}-y_{n}\right\|$. From (3.11) and (3.5), we get

$$
\lim _{n \rightarrow \infty}\left\|x_{n}-y_{n}\right\|=0 \text {. }
$$

Again by using the triangle inequality, we have for $j=1,2,3, \ldots, m$

$$
\left\|K_{n}^{j} y_{n}-p\right\| \leq\left\|K_{n}^{j} y_{n}-y_{n}\right\|+\left\|y_{n}-p\right\| .
$$

Since $x_{n} \rightarrow p$ and $\left\|x_{n}-y_{n}\right\| \rightarrow 0$, then $y_{n} \rightarrow p$ as $n \rightarrow \infty$. From (3.21), we get

$$
\lim _{n \rightarrow \infty}\left\|K_{n}^{j} y_{n}-p\right\|=0, \quad \forall j=1,2,3, \ldots, m .
$$

Using the triangle inequality, we obtain

$$
\left\|K_{n}^{j} y_{n}-K_{n}^{j-1} y_{n}\right\| \leq\left\|K_{n}^{j} y_{n}-p\right\|+\left\|p-K_{n}^{j-1} y_{n}\right\| .
$$

From (3.23), we have

$$
\lim _{n \rightarrow \infty}\left\|K_{n}^{j} y_{n}-K_{n}^{j-1} y_{n}\right\|=0, \quad \forall j=1,2,3, \ldots, m .
$$


Since $\left\{r_{j, n}\right\} \subset[d, \infty)$, so

$$
\lim _{n \rightarrow \infty} \frac{\left\|K_{n}^{j} y_{n}-K_{n}^{j-1} y_{n}\right\|}{r_{j, n}}=0, \quad \forall j=1,2,3, \ldots, m .
$$

From Lemma 2.8, we get for $j=1,2,3, \ldots, m$

$$
F_{j}\left(K_{n}^{j} y_{n}, y\right)+\frac{1}{r_{j, n}}\left\langle y-K_{n}^{j} y_{n}, J K_{n}^{j} y_{n}-J K_{n}^{j-1} y_{n}\right\rangle \geq 0, \quad \forall y \in C .
$$

From the condition (A2) that

$$
\begin{array}{r}
\frac{1}{r_{j, n}}\left\langle y-K_{n}^{j} y_{n} J K_{n}^{j} y_{n}-J K_{n}^{j-1} y_{n}\right\rangle \geq F_{j}\left(y, K_{n}^{j} y_{n}\right), \\
\forall y \in C, \forall j=1,2,3, \ldots, m .
\end{array}
$$

From (3.23) and (3.25), we have

$$
0 \geq F_{j}(y, p), \quad \forall y \in C, \forall j=1,2,3, \ldots, m .
$$

For $t$ with $0<t \leq 1$ and $y \in C$, let $y_{t}=t_{y}+(1-t) p$. Then, we get that $y_{t} \in C$. From (3.26), it follows that

$$
F_{j}\left(y_{t}, p\right) \leq 0, \quad \forall y_{t} \in C, \forall j=1,2,3, \ldots, m .
$$

By the conditions (A1) and (A4), we have for $j=1,2,3, \ldots, m$

$$
\begin{aligned}
0 & =F_{j}\left(y_{t}, y_{t}\right) \\
& \leq t F_{j}\left(y_{t}, y\right)+(1-t) F_{j}\left(y_{t}, p\right) \\
& \leq t F_{j}\left(y_{t}, y\right) \\
& \leq F_{j}\left(y_{t}, y\right) .
\end{aligned}
$$

From the condition (A3) and letting $t \rightarrow 0$, This implies that $p \in \operatorname{GMEP}\left(\theta_{j}, A_{j}, \phi_{j}\right)$ for all $j=1,2,3, \ldots, m$. Therefore, $p \in \cap_{j=1}^{m} \operatorname{GMEP}\left(\theta_{j}, A_{j}, \varphi_{j}\right)$. Hence, from $(a)$ and $(b)$, we obtain $p \in \mathfrak{F}$.

Step 5: We show that $p=\Pi_{\mathfrak{F}}^{f} x_{0}$. Since $\mathfrak{F}$ is closed and convex set from Lemma 2.4, we have $\Pi_{\mathfrak{F}}^{f} x_{0}$ is single value, denoted by $v$. From $x_{n}=\Pi_{C_{n}}^{f} x_{0}$ and $v \in \mathfrak{F} \subset C_{n}$, we also have

$$
G\left(x_{n}, J x_{0}\right) \leq G\left(v, J x_{0}\right), \quad \forall n \geq 1
$$

By definition of $G$ and $f$, we know that, for each given $x, G(\xi, J x)$ is convex and lower semicontinuous with respect to $\xi$. So

$$
G\left(p, J x_{0}\right) \leq \liminf _{n \rightarrow \infty} G\left(x_{n}, J x_{0}\right) \leq \limsup _{n \rightarrow \infty} G\left(x_{n}, J x_{0}\right) \leq G\left(v, J x_{0}\right) .
$$

From definition of $\Pi_{\mathfrak{F}}^{f} x_{0}$ and $p \in \mathfrak{F}$, we can conclude that $v=p=\Pi_{\mathfrak{F}}^{f} x_{0}$ and $x_{n} \rightarrow p$ as $n \rightarrow \infty$. This completes the proof.

Setting $T_{n} \equiv T$ in Theorem 3.1, then we obtain the following result:

Corollary 3.2. Let $C$ be a nonempty closed and convex subset of a uniformly convex and uniformly smooth Banach space $E$. Let $T$ be a relatively quasi-nonexpansive mapping of $C$ into $E$ and $f: E \rightarrow \mathbb{R}$ be a convex lower semicontinuous mapping with $C \subset$ $\operatorname{int}(D(f))$. For each $j=1,2, \ldots, m$ let $\theta_{j}$ be a bifunction from $C \times C$ to $\mathbb{R}$ which satisfies conditions (A1)-(A4), $A_{j}: C \rightarrow E^{*}$ be a continuous and monotone mapping and $\phi_{j}: C$ $\rightarrow \mathbb{R}$ be a lower semicontinuous and convex function. Assume that 
$x_{1}=\Pi_{C_{1}}^{f} x_{0}$. For an initial point $x_{0} \in E$ with $x_{1}=\Pi_{C_{1}}^{f} x_{0}$ and $C_{1}=C$, we define the sequence $\left\{x_{n}\right\}$ as follows:

$$
\left\{\begin{array}{l}
y_{n}=J^{-1}\left(\alpha_{n} J x_{n}+\left(1-\alpha_{n}\right) J T x_{n}\right), \\
u_{n}=T_{r_{m, n}}^{F_{m}} T_{r_{m-1, n}}^{F_{m-1}} \ldots, T_{r_{2}, n}^{F_{2}} T_{r_{1, n}}^{F_{1}} y_{n}, \\
C_{n+1}=\left\{z \in C_{n}: G\left(z, J u_{n}\right) \leq G\left(z, J y_{n}\right) \leq G\left(z, J x_{n}\right)\right\}, \\
x_{n+1}=\Pi_{C_{n+1}}^{f} x_{0}, \quad n \geq 1,
\end{array}\right.
$$

where $J$ is the duality mapping on $E,\left\{\alpha_{n}\right\}$ is a sequence in $[0,1]$ and $\left\{r_{j, n}\right\}_{n=1}^{\infty} \subset[d, \infty)$ for some $d>0(j=1,2, \ldots, m)$. If $\lim \inf _{n \rightarrow \infty}\left(1-\alpha_{n}\right)>0$, then $\left\{x_{n}\right\}$ converges strongly to $p \in \mathfrak{F}$, where $p=\Pi_{\mathfrak{F}}^{f} x_{0}$.

Remark 3.3. Corollary 3.2 extends and improves the result of Li et al. [26].

Taking $f(x)=0$ for all $x \in E$, we have $G(\xi, J x)=\varphi(\xi, x)$ and $\Pi_{C}^{f} x=\Pi_{C} x$. By Theorem 3.1, then we obtain the following Corollaries:

Corollary 3.4. Let $C$ be a nonempty closed and convex subset of a uniformly convex and uniformly smooth Banach space E. Let $\left\{T_{n}\right\}_{n=1}^{\infty}$ be a countable family of relatively quasi-nonexpansive mappings of $C$ to $E$ satisfy the (*) condition. For each $j=1,2, \ldots, m$ let $\theta_{j}$ be a bifunction from $C \times C$ to $\mathbb{R}$ which satisfies conditions (A1)-(A4), $A_{j}: C \rightarrow E^{*}$ be a continuous and monotone mapping, and $\phi_{j}: C \rightarrow \mathbb{R}$ be a lower semicontinuous and convex function. Assume that $\mathfrak{F}:=\left(\cap_{n=1}^{\infty} F\left(T_{n}\right)\right) \cap\left(\cap_{j=1}^{m} \operatorname{GMEP}\left(\theta_{j}, A_{j}, \varphi_{j}\right)\right) \neq \emptyset$. For an initial point $x_{0} \in E$ with $x_{1}=\Pi_{C_{1}} x_{0}$ and $C_{1}=C$, we define the sequence $\left\{x_{n}\right\}$ as follows:

$$
\left\{\begin{array}{l}
y_{n}=J^{-1}\left(\alpha_{n} J x_{n}+\left(1-\alpha_{n}\right) J T_{n} x_{n}\right) \\
u_{n}=T_{r_{m, n}}^{F_{m}} T_{r_{m-1, n}}^{F_{m}} \ldots, T_{r_{2, n}}^{F_{2}} T_{r_{1, n}}^{F_{1}} y_{n} \\
C_{n+1}=\left\{z \in C_{n}: \phi\left(z, u_{n}\right) \leq \phi\left(z, J y_{n}\right) \leq \phi\left(z, x_{n}\right)\right\} \\
x_{n+1}=\prod_{C_{n+1}} x_{0}, \quad n \geq 1
\end{array}\right.
$$

where $J$ is the duality mapping on $E,\left\{\alpha_{n}\right\}$ is a sequence in $[0,1]$ and $\left\{r_{j, n}\right\}_{n=1}^{\infty} \subset[d, \infty)$ for some $d>0(j=1,2, \ldots, m)$. If $\lim \inf _{n \rightarrow \infty}\left(1-\alpha_{n}\right)>0$, then $\left\{x_{n}\right\}$ converges strongly to $p \in \mathfrak{F}$, where $p=\Pi_{\mathfrak{F}} x_{0}$.

Remark 3.5. Corollary 3.4 extends and improves the result of Shehu [[45], Theorem 3.1] form finite family of relatively quasi-nonexpansive mappings to a countable family of relatively quasi-nonexpansive mappings.

\section{Applications}

\subsection{A zero of $\mathcal{B}$-monotone mappings}

Let $\mathcal{B}$ be a mapping from $E$ to $E^{*}$. A mapping $\mathcal{B}$ is said to be

1. monotone if $\langle\mathcal{B} x-\mathcal{B} y, x-y\rangle \geq 0$ for all $x, y \in E$;

2. strictly monotone if $\mathcal{B}$ monotone and $\langle\mathcal{B} x-\mathcal{B} y, x-y\rangle=0$ if and only if $x=y$;

3. $\beta$-Lipschitz continuous if there exist a constant $\beta \geq 0$ such that $\|\mathcal{B} x-\mathcal{B} y\| \leq \beta\|x-y\|$ for all $x, y \in E$.

Let $M$ be a set-valued mapping from $E$ to $E^{*}$ with domain $D(M)=\{z \in E: M z \neq 0\}$ and range $R(M)=\cup\{M z: z \in D(M)\}$. A set value mapping $M$ is said to be 
(i) monotone if $\left\langle x_{1}-x_{2}, y_{1}-y_{2}\right\rangle \geq 0$ for each $x_{i} \in D(M)$ and $y_{i} \in M x_{i}, i=1,2$;

(ii) $r$-strongly monotone if $\left\langle x_{1}-x_{2}, y_{1}-y_{2}\right\rangle \geq r|| x_{1}-x_{2}||$ for each $x_{i} \in D(M)$ and $y_{i} \in$ $M x_{i}, i=1,2$;

(iii) maximal monotone if $M$ is monotone and its graph $\mathfrak{G}(M)=\{(x, y): y \in M x\}$ is not properly contained in the graph of any other monotone mapping;

(iv) general $\mathcal{B}$-monotone if $M$ is monotone and $(\mathcal{B}+\lambda M) E=E *$ holds for every $\lambda$ $>0$, where $\mathcal{B}$ is a mapping from $E$ to $E^{*}$.

We consider the problem of finding a point $x^{*} \in E$ satisfying $0 \in M x^{*}$. We denote by $M^{-1} 0$ the set of all points $x^{*} \in E$ such that $0 \in M x^{*}$, where $M$ is maximal monotone operator from $E$ to $E^{* *}$.

Lemma 4.1. [26] Let $E$ be a Banach space with the dual space $E^{*}, \mathcal{B}: E \rightarrow E *$ be a strictly monotone mapping, and $M: E \rightarrow 2^{E_{*}}$ be a general $\mathcal{B}$-monotone mapping. Then $M$ is maximal monotone mapping.

Remark 4.2. [26] Let $E$ be a Banach space with the dual space $E^{*}, \mathcal{B}: E \rightarrow E *$ be a strictly monotone mapping, and $M: E \rightarrow 2^{E_{*}^{*}}$ be a general $\mathcal{B}$-monotone mapping. Then $M$ is a maximal monotone mapping. Therefore, $M^{-1} 0=\{z \in D(M): 0 \in M z\}$ is closed and convex.

Lemma 4.3. [17]Let $E$ be a uniformly convex and uniformly smooth Banach space, $\delta_{E}$ $(\varepsilon)$ be the modulus of convexity of $E$, and $\rho_{E}(t)$ be the modulus of smoothness of $E$; then the inequalities

$$
8 d^{2} \delta_{E}(\|x-\xi\| / 4 d) \leq \phi(x, \xi) \leq 4 d^{2} \rho_{E}(4\|x-\xi\| / d)
$$

hold for all $x$ and $\xi$ in $E$, where $d=\sqrt{\left(\|x\|^{2}+\|\xi\|^{2}\right) / 2}$.

Lemma 4.4. [49] Let $E$ be a Banach space with the dual space $E^{*}, \mathcal{B}: E \rightarrow E * b e$ a strictly monotone mapping, and $M: E \rightarrow 2^{E_{*}}$ be a general $\mathcal{B}$-monotone mapping. Then

1. $(\mathcal{B}+\lambda M)^{-1}$ is single value;

2. if $E$ is reflexive and $M: E \rightarrow 2^{E_{*}}$ a r-strongly monotone mapping, then $(\mathcal{B}+\lambda M)^{-1}$ is Lipschitz continuous with constant $\frac{1}{\lambda r}$, where $r>0$.

From Lemma 4.4 we note that let $E$ be a Banach space with the dual space $E^{*}$, $\mathcal{B}: E \rightarrow E *$ a strictly monotone mapping, and $M: E \rightarrow 2^{E_{* *}}$ a general $\mathcal{B}$-monotone mapping, for every $\lambda>0$ and $x^{*} \in E^{*}$; then there exists a unique $x \in D(M)$ such that $x=(\mathcal{B}+\lambda M)^{-1} x^{*}$. We can define a single-valued mapping $T_{\lambda}: E \rightarrow D(M)$ by $T_{\lambda} x=(\mathcal{B}+\lambda M)^{-1} \mathcal{B} x$. It is easy to see that $M^{-1} 0=F\left(T_{\lambda}\right)$ for all $\lambda>0$. Indeed, we have

$$
\begin{aligned}
z \in M^{-1} 0 & \Leftrightarrow 0 \in M z \\
& \Leftrightarrow 0 \in \lambda M z \\
& \Leftrightarrow \mathcal{B} z \in(\mathcal{B}+\lambda M) z \\
& \Leftrightarrow z=(\mathcal{B}+\lambda M)^{-1} \mathcal{B} z=T_{\lambda} z \\
& \Leftrightarrow z \in F\left(T_{\lambda}\right), \forall \lambda>0 .
\end{aligned}
$$

Motivated by Li et al. [26] we obtain the following result:

Theorem 4.5. Let $C$ be a nonempty closed and convex subset of a uniformly convex and uniformly smooth Banach space $E$ with $\delta_{E}(\varepsilon) \geq k \varepsilon^{2}$ and $\rho_{E}(t) \leq c t^{2}$ for some $c, k>0$, and $E^{*}$ be the dual space of $E$. Let $\mathcal{B}: E \rightarrow E *$ be a strictly monotone and $\beta$-Lipschitz 
continuous mapping, and let $M: E \rightarrow 2^{E_{*}^{*}}$ be a general $\mathcal{B}$-monotone and $r$-strongly monotone mapping with $r>0$. Let $\left\{T_{\lambda_{n}}\right\}=\left(\mathcal{B}+\lambda_{n} M\right)^{-1} \mathcal{B}$ satisfy the (*)-condition and $f$ : $E \rightarrow \mathbb{R}$ be a convex lower semicontinuous mapping with $C \subset \operatorname{int}(D(f))$ and suppose that for each $n \geq 0$ there exists $\lambda_{n}>0$ such that $64 c \beta^{2} \leq \min \left\{\frac{1}{2} k \lambda_{n}^{2} r^{2}\right\}$. For each $j=1,2, \ldots$, $m$ let $\theta_{j}$ be a bifunction from $C \times C$ to $\mathbb{R}$ which satisfies conditions (A1)-(A4), $A_{j}: C \rightarrow$ $E^{*}$ be a continuous and monotone mapping, and $\phi_{j}: C \rightarrow \mathbb{R}$ be a lower semicontinuous and convex function. Assume that $\mathfrak{F}:=M^{-1} 0 \cap\left(\cap_{j=1}^{m} \operatorname{GMEP}\left(\theta_{j}, A_{j}, \varphi_{j}\right)\right) \neq \emptyset$. For an initial point $x_{0} \in E$ with $x_{1}=\Pi_{C_{1}}^{f} x_{0}$ and $C_{1}=C$, we define the sequence $\left\{x_{n}\right\}$ as follows:

$$
\left\{\begin{array}{l}
y_{n}=J^{-1}\left(\alpha_{n} J x_{n}+\left(1-\alpha_{n}\right) J T_{\lambda_{n}} x_{n}\right), \\
u_{n}=T_{r_{m, n}}^{F_{m}} T_{r_{m-1, n}}^{F_{m-1}}, \ldots, T_{r_{2, n}}^{F_{2}} T_{r_{1, n}}^{F_{1}} y_{n}, \\
C_{n+1}=\left\{z \in C_{n}: G\left(z, J u_{n}\right) \leq G\left(z, J y_{n}\right) \leq G\left(z, J x_{n}\right)\right\}, \\
x_{n+1}=\Pi_{C_{n+1}}^{f} x_{0}, \quad n \geq 1,
\end{array}\right.
$$

where $J$ is the duality mapping on $E$ and $\left\{\alpha_{n}\right\}$ is a sequence in $[0,1]$, and $\left\{r_{j, n}\right\}_{n=1}^{\infty} \subset[d, \infty)$ for some $d>0(j=1,2, \ldots, m)$. If $\lim _{\inf _{n \rightarrow \infty}}\left(1-\alpha_{n}\right)>0$, then $\left\{x_{n}\right\}$ converges strongly to $p \in \mathfrak{F}$ where $p=\Pi_{\mathfrak{F}}^{f} x_{0}$.

Proof We show that $\left\{T_{\lambda_{n}}\right\}$ is a family of relatively quasi-nonexpansive mappings with common fixed point $\cap_{n=1}^{\infty} F\left(T_{\lambda_{n}}\right)=M^{-1} 0$. We only show that $\phi\left(p, T_{\lambda_{n}} q\right) \leq \phi(p, q), \forall q \in$ $E, p \in F\left(T_{\lambda_{n}}\right), n \geq 1$. From Lemma 4.3 , and $\mathcal{B}$ is a $\beta$-Lipschitz continuous mapping, we have

$$
\begin{aligned}
\phi\left(p, T_{\lambda_{n}} q\right) & =\phi\left(T_{\lambda_{n}} p, T_{\lambda_{n}} q\right) \\
& \leq 4 d^{2} \rho_{E}\left(\frac{4\left\|T_{\lambda_{n}} p-T_{\lambda_{n}} q\right\|}{d}\right) \\
& \leq 64 c\left\|T_{\lambda_{n}} p-T_{\lambda_{n}} q\right\|^{2} \\
& =64 c\left\|\left(\mathcal{B}+\lambda_{n} M\right)^{-1} \mathcal{B} p-\left(\mathcal{B}+\lambda_{n} M\right)^{-1} \mathcal{B} q\right\|^{2} \\
& \leq \frac{64 c}{\lambda_{n}^{2} r^{2}}\|\mathcal{B} p-\mathcal{B} q\|^{2} \\
& \leq \frac{64 \beta^{2}}{\lambda_{n}^{2} r^{2}}\|p-q\|^{2}
\end{aligned}
$$

and we also have

$$
\phi(p, q) \geq 8 d^{2} \delta_{E}\left(\frac{\|p-q\|}{4 d}\right) \geq \frac{1}{2} k\|p-q\|^{2} .
$$

Since

$$
64 c \beta^{2} \leq \frac{1}{2} k \lambda_{n}^{2} r^{2}
$$

it follows from (4.3) and (4.4) that $\phi\left(p, T_{\lambda_{n}} q\right) \leq \phi(p, q)$ for all $q \in E, p \in F\left(T_{\lambda_{n}}\right), n \geq$ 1. Therefore, $\left\{T_{\lambda_{n}}\right\}$ is a family of relatively quasi-nonexpansive mapping. It follows from Theorem 3.1, so the desired conclusion follows.

\subsection{A zero point of maximal monotone operators}

In this section, we apply our results to find zeros of maximal monotone operator. Such a problem contains numerous problems in optimization, economics, and physics. The following result is also well known.

Lemma 4.6. [50]Let $E$ be a reflexive strictly convex and smooth Banach space and let $M$ be a monotone operator from $E$ to $E^{*}$. Then $M$ is maximal if and only if $R(J+\lambda M)$ $=E^{*}$ for all $\lambda>0$. 
Let $E$ be a reflexive strictly convex and smooth Banach space, $\mathcal{B}=J$ and let $M$ be a maximal monotone operator from $E$ to $E^{*}$. Using Lemma 4.6 and strict convexity of $E$, we obtain that for every $\lambda>0$ and $x \in E$, there exists a unique $x_{\lambda}$ such that $J x \in\left(J x_{\lambda}+\right.$ $\left.\lambda M x_{\lambda}\right)$. Then we can defined a single-valued mapping $J_{\lambda}: E \rightarrow D(M)$ by $J_{\lambda}=(J+\lambda M)^{-}$ ${ }^{1} \mathrm{~J}$ and $J_{\lambda}$ is called the resolvent of $M$. We know that $M^{-1} 0=F\left(J_{\lambda}\right)[21,51]$.

Theorem 4.7. Let $C$ be a nonempty closed and convex subset of a uniformly convex and uniformly smooth Banach space $E$ with the dual space $E^{*}$. Let $M \subset E \times E^{*}$ be a maximal monotone mapping and $D(M) \subset C \subset J^{-1}\left(\cap_{\lambda_{n}>0} R\left(J+\lambda_{n} M\right)\right.$. Let $\left\{J_{\lambda_{n}}\right\}=\left(J+\lambda_{n} M\right)^{-1}$ Jsatisfy the $\left(^{*}\right)$-condition where $\lambda_{n}>0$ be the resolvement of $M$ and $f$ : $E \rightarrow \mathbb{R}$ be a convex lower semicontinuous mapping with $C \subset \operatorname{int}(D(f))$. For each $j=1$, $2, \ldots, m$ let $\theta_{j}$ be a bifunction from $C \times C$ to $\mathbb{R}$ which satisfies conditions (A1)-(A4), $A j$ : $C \rightarrow E^{*}$ be a continuous and monotone mapping, and $\phi_{j}: C \rightarrow \mathbb{R}$ be a lower semicontinuous and convex function. Assume that $\mathfrak{F}=M^{-1} 0 \bigcap\left(\cap_{j=1}^{m} \operatorname{GMEP}\left(\theta_{j}, A_{j}, \varphi_{j}\right)\right) \neq \emptyset$. For an initial point $x_{0} \in E$ with $x_{1}=\Pi_{C_{1}}^{f} x_{0}$ and $C_{1}=C$, we define the sequence $\left\{x_{n}\right\}$ as follows:

$$
\left\{\begin{array}{l}
y_{n}=J^{-1}\left(\alpha_{n} J x_{n}+\left(1-\alpha_{n}\right) J J_{\lambda_{n}} x_{n}\right), \\
u_{n}=T_{r_{m, n}}^{F_{m}} T_{r_{m-1, n}}^{F_{m-1}}, \ldots, T_{r_{2, n}}^{F_{2}} T_{r_{1, n}}^{F_{1}} y_{n}, \\
C_{n+1}=\left\{z \in C_{n}: G\left(z, J u_{n}\right) \leq G\left(z, J y_{n}\right) \leq G\left(z, J x_{n}\right)\right\}, \\
x_{n+1}=\Pi_{C_{n+1}}^{f} x_{0}, \quad n \geq 1,
\end{array}\right.
$$

where $J$ is the duality mapping on $E$ and $\left\{\alpha_{n}\right\}$ is a sequence in $[0,1]$ and $\left\{r_{j, n}\right\}_{n=1}^{\infty} \subset[d, \infty)$ for some $d>0(j=1,2, \ldots, m)$. If $\lim _{\inf _{n \rightarrow \infty}}\left(1-\alpha_{n}\right)>0$, then $\left\{x_{n}\right\}$ converges strongly to $p \in \mathfrak{F}$, where $p=\Pi_{\mathfrak{F}}^{f} x_{0}$.

Proof First, we have $\cap_{n=1}^{\infty} F\left(J_{\lambda_{n}}\right)=M^{-1} 0 \neq \emptyset$. Second, from the monotonicity of $M$, let $p \in \cap_{n=1}^{\infty} F\left(J_{\lambda_{n}}\right)$ and $q \in E$; we have

$$
\begin{aligned}
\phi\left(p, J_{\lambda_{n}} q\right) & =\|p\|^{2}-2\left\langle p, J J_{\lambda_{n}} q\right\rangle+\left\|J_{\lambda_{n}} q\right\|^{2} \\
& =\|p\|^{2}+2\left\langle p, J q-J J_{\lambda_{n}} q-J q\right\rangle+\left\|J_{\lambda_{n}} q\right\|^{2} \\
& =\|p\|^{2}+2\left\langle p, J q-J J_{\lambda_{n}} q\right\rangle-2\langle p, J q\rangle+\left\|J_{\lambda_{n}} q\right\|^{2} \\
& =\|p\|^{2}-2\left\langle J_{\lambda_{n}} q-p-J_{\lambda_{n}} q, J q-J J_{\lambda_{n}} q\right\rangle-2\langle p, J q\rangle+\left\|J_{\lambda_{n}} q\right\|^{2} \\
& =\|p\|^{2}-2\left\langle J_{\lambda_{n}} q-p, J q-J J_{\lambda_{n}} q\right\rangle+2\left\langle J_{\lambda_{n}} q, J q-J J_{\lambda_{n}} q\right\rangle-2\langle p, J q\rangle+\left\|J_{\lambda_{n}} q\right\|^{2} \\
& \leq\|p\|^{2}+2\left\langle J_{\lambda_{n}} q, J q-J J_{\lambda_{n}} q\right\rangle-2\langle p, J q\rangle+\left\|J_{\lambda_{n}} q\right\|^{2} \\
& =\|p\|^{2}-2\langle p, J q\rangle+\|q\|^{2}-\left\|J_{\lambda_{n}} q\right\|^{2}+2\left\langle J_{\lambda_{n}} q, J q\right\rangle-\|q\|^{2} \\
& =\phi(p, q)-\phi\left(J_{\lambda_{n}} q, q\right) \\
& \leq \phi(p, q)
\end{aligned}
$$

for all $n \geq 1$. Therefore, $\left\{J_{\lambda_{n}}\right\}$ is a family of relatively quasi-nonexpansive mapping for all $\lambda_{n}>0$ with the common fixed point set $\cap_{n=1}^{\infty} F\left(J_{\lambda_{n}}\right)=M^{-1} 0$. Hence, it follows from Theorem 3.1, the desired conclusion follows:

\section{Acknowledgements}

The authors are greatly indebted to Professor Simeon Reich and the reviewers for their extremely constructive comments and valuable suggestions leading to the revised version. Ms. Siwaporn Saewan was supported by grant from under the program Strategic Scholarships for Frontier Research Network for the Join Ph.D. Program Thai Doctoral degree from the Office of the Higher Education Commission, Thailand and the King Mongkuts Diamond scholarship for the Ph.D. program at King Mongkuts University of Technology Thonburi (KMUTT; under NRU-CSEC project no.54000267). Furthermore, this research was supported by the Center of Excellence in Mathematics, the Commission on Higher Education, Thailand (under the project no.RG-1-53-03-2). 


\section{Author details}

'Department of Mathematics, Faculty of Science King Mongkut's University of Technology Thonburi (KMUTT) Bangmod, Bangkok 10140, Thailand ${ }^{2}$ Centre of Excellence in Mathematics, CHE Si Ayutthaya Rd., Bangkok 10400, Thailand

\section{Authors' contributions}

All authors read and approved the final manuscript.

\section{Competing interests}

The authors declare that they have no competing interests.

Received: 23 July 2011 Accepted: 21 December 2011 Published: 21 December 2011

\section{References}

1. Blum, E, Oettli, W: From optimization and variational inequalities to equilibrium problems. Math Student. 63, 123-145 (1994)

2. Cholamjiak, W, Suantai, S: Convergence analysis for a system of equilibrium problems and a countable family of relatively quasi-nonexpansive mappings in Banach spaces. Abs Appl Anal 2010, 17 (2010). (Article ID 141376)

3. Combettes, PL, Hirstoaga, SA: Equilibrium programming in Hilbert spaces. J Nonlinear Convex Anal. 6, 117-136 (2005)

4. Qin, X, Cho, YJ, Kang, SM: Convergence theorems of common elements for equilibrium problems and fixed point problems in Banach spaces. J Comput Appl Math. 225, 20-30 (2009). doi:10.1016/j.cam.2008.06.011

5. Saewan, S, Kumam, P: Modified hybrid block iterative algorithm for convex feasibility problems and generalized equilibrium problems for uniformly quasi- $\phi$-asymptotically nonexpansive mappings. Abs Appl Anal 2010, 22 (2010). (Article ID 357120)

6. Saewan, S, Kumam, P: A new modified block iterative algorithm for uniformly quasi- $\phi$-asymptotically nonexpansive mappings and a system of generalized mixed equilibrium problems. Fixed Point Theory Appl. 2011, 35 (2011). doi:10.1186/1687-1812-2011-35

7. Saewan, S, Kumam, P: A modified hybrid projection method for solving generalized mixed equilibrium problems and fixed point problems in Banach spaces. Comput Math Appl. 62, 1723-1735 (2011). doi:10.1016/j.camwa.2011.06.014

8. Saewan, S, Kumam, P: Strong convergence theorems for countable families of uniformly quasi- $\phi$-asymptotically nonexpansive mappings and a system of generalized mixed equilibrium problems. Abs Appl Anal 2011, 27 (2011). (Article ID 701675)

9. Saewan, S, Kumam, P: The shrinking projection method for solving generalized equilibrium problem and common fixed points for asymptotically quasi- $\phi$-nonexpansive mappings. Fixed Point Theory Appl. 2011, 9 (2011). doi:10.1186/16871812-2011-9

10. Saewan, S, Kumam, P: Convergence theorems for mixed equilibrium problems, variational inequality problem and uniformly quasi- $\phi$-asymptotically nonexpansive mappings. Appl Math Comput. 218, 3522-3538 (2011). doi:10.1016/j. amc.2011.08.099

11. Saewan, S, Kumam, P, Wattanawitoon, K: Convergence theorem based on a new hybrid projection method for finding a common solution of generalized equilibrium and variational inequality problems in Banach spaces. Abs Appl Anal 2010, 26 (2010). (Article ID 734126)

12. Takahashi, W, Zembayashi, K: Strong and weak convergence theorems for equilibrium problems and relatively nonexpansive mappings in Banach spaces. Nonlinear Anal. 70, 45-57 (2009). doi:10.1016/j.na.2007.11.031

13. Takahashi, W, Zembayashi, K: Strong convergence theorem by a new hybrid method for equilibrium problems and relatively nonexpansive mappings. Fixed Point Theory Appl 2008, 11 (2008). (Article ID 528476)

14. Wattanawitoon, K, Kumam, P: A strong convergence theorem by a new hybrid projection algorithm for fixed point problems and equilibrium problems of two relatively quasi-nonexpansive mappings. Nonlinear Anal Hyb Syst. 3, 11-20 (2009). doi:10.1016/j.nahs.2008.10.002

15. Wattanawitoon, K, Kumam, P: Generalized mixed equilibrium problems for maximal monotone operators and two relatively quasi-nonexpansive mappings. Thai J Math. 9, 165-189 (2011)

16. Zhang, S: Generalized mixed equilibrium problem in Banach spaces. Appl Math Mech Engl Ed. 30, 1105-1112 (2009). doi:10.1007/s10483-009-0904-6

17. Alber, Y: Metric and generalized projection operators in Banach spaces: Properties and applications. In: Kartsatos A (ed.) Theory and Applications of Nonlinear Operators of Accretive and Monotone Type. pp. 15-50. Marcel Dekker, New York (1996)

18. Alber, Y, Reich, S: An iterative method for solving a class of nonlinear operator equations in Banach spaces. Panamer Math J. 4, 39-54 (1994)

19. Cioranescu, I: Geometry of Banach spaces. Duality Mappings and Nonlinear Problems. Kluwer, Dordrecht (1990)

20. Kamimura, S, Takahashi, W: Strong convergence of a proximal-type algorithm in a Banach space. SIAM J Optim. 13, 938-945 (2002). doi:10.1137/S105262340139611X

21. Takahashi, W: Nonlinear Functional Analysis. Yokohama Publishers, Yokohama (2000)

22. Li, JL: The generalized projection operator on reflexive Banach spaces and its applications. J Math Anal Appl. 306 55-71 (2005). doi:10.1016/j.jmaa.2004.11.007

23. Alber, Y: Generalized projection operators in Banach spaces: Properties and applications. Proceedings of the Israel Seminar Ariel, Israel Funct Differ Equ. 1, 1-21 (1994)

24. $\mathrm{Wu}, \mathrm{KQ}$, Huang, NJ: The generalized f-projection operator with an application. Bull Aust Math Soc. 73, 307-317 (2006). doi:10.1017/S0004972700038892

25. Fan, JH, Liu, X, Li, JL: Iterative schemes for approximating solutions of generalized variational inequalities in Banach spaces. Nonlinear Anal TMA. 70, 3997-4007 (2009). doi:10.1016/j.na.2008.08.008

26. Li, X, Huang, N, O'Regan, D: Strong convergence theorems for relatively nonexpansive mappings in Banach spaces with applications. Comput Math Appl. 60, 1322-1331 (2010). doi:10.1016/j.camwa.2010.06.013 
27. Alber, Y, Butnariu, D: Convergence of Bregman projection methods for solving consistent convex feasibility problems in reflexive Banach spaces. J Optim Theory Appl. 92, 33-61 (1997). doi:10.1023/A:1022631928592

28. Reich, S: A weak convergence theorem for the alternating method with Bregman distances. In: Kartsatos AG (ed.) Theory and Applications of Nonlinear Operators of Accretive and Monotone Type. pp. 313-318. Marcel Dekker, New York (1996)

29. Nilsrakoo, W, Saejung, S: Strong convergence to common fixed points of countable relatively quasi-nonexpansive mappings. Fixed Point Theory Appl 2008, 19 (2008). (Article ID 312454)

30. Su, Y, Wang, D, Shang, M: Strong convergence of monotone hybrid algorithm for hemi-relatively nonexpansive mappings. Fixed Point Theory Appl 2008, 8 (2008). (Article ID 284613)

31. Zegeye, H, Shahzad, N: Strong convergence for monotone mappings and relatively weak nonexpansive mappings. Nonlinear Anal. 70, 2707-2716 (2009). doi:10.1016/..na.2008.03.058

32. Butnariu, D, Reich, S, Zaslavski, AJ: Asymptotic behavior of relatively nonexpansive operators in Banach spaces. J Appl Anal. 7, 151-174 (2001). doi:10.1515/JAA.2001.151

33. Butnariu, D, Reich, S, Zaslavski, AJ: Weak convergence of orbits of nonlinear operators in reflexive Banach spaces. Numer Funct Anal Optim. 24, 489-508 (2003). doi:10.1081/NFA-120023869

34. Censor, Y, Reich, S: Iterations of paracontractions and firmly nonexpansive operators with applications to feasibility and optimization. Optimization. 37, 323-339 (1996). doi:10.1080/02331939608844225

35. Matsushita, S, Takahashi, W: A strong convergence theorem for relatively nonexpansive mappings in a Banach space. J Approx Theory. 134, 257-266 (2005). doi:10.1016/j.jat.2005.02.007

36. $\mathrm{Su}, \mathrm{Y}$, Wang, $\mathrm{Z}, \mathrm{Xu}, \mathrm{HK}$ : Strong convergence theorems for a common fixed point of two hemi-relatively nonexpansive mappings. Nonlinear Anal. 71, 5616-5628 (2009). doi:10.1016/.jna.2009.04.053

37. Mann, WR: Mean value methods in iteration. Proc Am Math Soc. 4, 506-510 (1953). doi:10.1090/50002-9939-19530054846-3

38. Reich, S: Weak convergence theorems for nonexpansive mappings in Banach spaces. J Math Anal Appl. 67, 274-276 (1979). doi:10.1016/0022-247X(79)90024-6

39. Genel, A, Lindenstrauss, J: An example concerning fixed points. Israel J Math. 22, 81-86 (1975). doi:10.1007/BF02757276

40. Bauschke, HH, Matouskova, E, Reich, S: Projection and proximal point methods: Convergence results and counterexamples. Nonlinear Anal. 56, 715-738 (2004). doi:10.1016/j.na.2003.10.010

41. Nakajo, K, Takahashi, W: Strong convergence theorems for nonexpansive mappings and nonexpansive semigroups. J Math Anal Appl. 279, 372-379 (2003). doi:10.1016/S0022-247X(02)00458-4

42. Aoyama, K, Kimura, Y, Takahashi, W, Toyoda, M: Approximation of common fixed points of a countable family of nonexpansive mappings in a Banach space. Nonlinear Anal. 67, 2350-2360 (2007). doi:10.1016/j.na.2006.08.032

43. Takahashi, W, Takeuchi, Y, Kubota, R: Strong convergence theorems by hybrid methods for families of nonexpansive mappings in Hilbert spaces. J Math Anal Appl. 341, 276-286 (2008). doi:10.1016/j.jmaa.2007.09.062

44. Plubtieng, S, Ungchittrakool, $\mathrm{K}$ : Approximation of common fixed points for a countable family of relatively nonexpansive mappings in a Banach space and applications. Nonlinear Anal. 72, 2896-2908 (2010). doi:10.1016/j. na.2009.11.034

45. Shehu, Y: Iterative approximation method for finite family of relatively quasi nonexpansive mappings and systems of equilibrium problems. J Glob Optim (in press). Doi:10.1007/s10898-010-9619-4

46. Boonchari, D, Saejung, S: Approximation of common fixed points of a countable family of relatively nonexpansive mappings. Fixed Point Theory Appl 2010, 26 (2010). (Article ID 407651)

47. Shehu, Y: A new iterative scheme for countable families of weak relatively nonexpansive mappings and system of generalized mixed equilibrium problems. Abs Appl Anal 2010, 24 (2010). (Article ID 861031)

48. Deimling, K: Nonlinear Functional Analysis. Springer, Berlin (1985)

49. Xia, FQ, Huang, NJ: Variational inclusions with a general $\mathrm{H}$ monotone operator in Banach spaces. Comput Math Appl. 54, 24-30 (2007). doi:10.1016/j.camwa.2006.10.028

50. Rockafellar, RT: On the maximality of sums of nonlinear monotone operators. Trans Am Math Soc. 149, 75-88 (1970). doi:10.1090/50002-9947-1970-0282272-5

51. Takahashi, W: Convex Analysis and Approximation Fixed Points. Yokohama Publishers, Yokohama (2009)

doi:10.1186/1687-1812-2011-104

Cite this article as: Saewan and Kumam: A modified Mann iterative scheme by generalized $f$-projection for a countable family of relatively quasi-nonexpansive mappings and a system of generalized mixed equilibrium problems. Fixed Point Theory and Applications 2011 2011:104.

\section{Submit your manuscript to a SpringerOpen ${ }^{\circ}$ journal and benefit from:}

- Convenient online submission

- Rigorous peer review

- Immediate publication on acceptance

- Open access: articles freely available online

- High visibility within the field

- Retaining the copyright to your article

Submit your next manuscript at $\gg$ springeropen.com 